\title{
Clinical outcomes of an ultrathin-strut sirolimus-eluting stent in all-comers population: Thailand Orsiro registry
}

\author{
Pannipa Suwannasom', Siriporn Athiksakul' ${ }^{2}$ Tasalak Thonghong ${ }^{1}$, Vorarit Lertsuwunseri², \\ Jarkarpun Chaipromprasit ${ }^{2}$, Suphot Srimahachota ${ }^{2}$, Wasan Udayachalerm² ${ }^{2}$ Srun Kuanprasert ${ }^{1}$ and \\ Wacin Buddhari ${ }^{2 *}$
}

\begin{abstract}
Background: Despite numerous studies supporting the outperformance of ultrathin-strut bioresorbable polymer sirolimus-eluting stent (Orsiro SES, Biotronik AG), the generalizability of the study results remains unclear in the Asian population. We sought to evaluate the clinical outcomes of the Orsiro SES in unselected Thai population.
\end{abstract}

Methods: The Thailand Orsiro registry was a prospective, open-label clinical study evaluating all patients with obstructive coronary artery disease implanted with Orsiro SES. The primary endpoint was target lesion failure (TLF) at 12 months. TLF is defined as a composite of cardiac death, target vessel myocardial infarction (TVMI), emergent coronary artery bypass graft (CABG), and clinically driven target lesion revascularization (CD-TLR). Patients with diabetes, small vessels ( $\leq 2.75 \mathrm{~mm}$ ), chronic total occlusions (CTOs), and acute myocardial infarction (AMI) were pre-specified subgroups for statistical analysis.

Result: A total of 150 patients with 235 lesions were included in the analysis. Half of the patients (53.3\%) presented with AMI, and 24\% had diabetes. Among 235 lesions, 93(39.4\%) were small vessels, and 24(10.2\%) were chronic total occlusions. The primary endpoint, TLF at 12 months, occurred in eight patients (5.3\%), predominately caused by cardiac death. By contrast, the incidences of TVMI and CD-TLR were null. The outcomes in pre-specified subgroup were not different from the overall population (all $p>0.05$ ). One definite late stent thrombosis $(0.7 \%)$ was incidentally observed during primary percutaneous coronary intervention to the non-target vessel.

Conclusion: The safety and efficacy of the ultrathin strut sirolimus-eluting stent in unselected cases are confirmed in the Thailand Orsiro registry. Despite the high proportion of pre-specified high-risk subgroups, the excellent stent performance was consistent with the overall population.

Trial Registration TCTR20190325001.

Keywords: Ultrathin-strut, Sirolimus, All-comer, Registry

*Correspondence: wacin_buddhari@hotmail.com

2 Division of Cardiology, Department of Medicine, King Chulalongkorn

Memorial Hospital, 1873 Rama IV Rd., Pathumwan, Bangkok 10330,

Thailand

Full list of author information is available at the end of the article

\section{Background}

Drug-eluting stents (DES) are a preferred treatment in patients with obstructive coronary artery disease(CAD) with coronary anatomy suitable for percutaneous coronary intervention (PCI) (1). One of the remarkable DES modification was the reduction of strut thickness with the preservation of radial strength (2). The reduction of 
strut thickness has mitigated vascular injury and promoted early strut coverage. Multiple meta-analyses have repeatedly reported that ultrathin strut DESs (defined as strut thickness $<70 \mu \mathrm{m}$ ) were associated with a lower incidence of target lesion failure (TLF) in comparison with contemporary second-generation DES (3-6).

The Orsiro bioresorbable polymer sirolimus-eluting stent (Orsiro SES) (Biotronik AG, Bülach, Switzerland) is one of the ultrathin stents platforms. The unique feature of Orsiro SES is a hybrid coating consists of passive and active coating. The passive coating is a layer of amorphous silicon carbide that reduces tissue inflammation and prevents thrombus adhesion $(7,8)$. The active coating is a layer of bioresorbable drug-polymer that released sirolimus. The clinical benefit of Orsiro SES has been widely demonstrated in many randomized controlled trials (9-13) and national registries (14-16). Recently, Orsiro SES has shown a superior reduction of TLF and late or very late stent thrombosis at the three-year followup compared with durable-polymer everolimus-eluting stents (9). In addition, the real-world clinical performance of Orsiro SES also showed favorable medium-(17) and long-term $(18,19)$ clinical outcomes.

Although numerous studies support the outperformance of the ultrathin strut bioresorbable polymer SES (9), the generalizability of the study results remains unclear in the Asian population since the data was predominantly derived from European centers. It would be of interest to investigate the safety and efficacy of the ultrathin strut BP-SES in real-world Asian population and predefined subgroups: diabetes patients, small vessels $(\leq 2.75 \mathrm{~mm})$, chronic total occlusion $(\mathrm{CTO})$, and acute myocardial infarction (AMI).

\section{Methods}

\section{Study design and population}

Thailand Orsiro registry was a prospective, non-randomised, multi-center, observational study to evaluate the safety and clinical performance of the Orsiro SES (Biotronik AG, Bülach, Switzerland) in real-world practice. The study was conducted at two high-volume centers in Thailand: King Chulalongkorn Memorial Hospital, Bangkok and Maharaj Nakorn Chiang Mai Hospital, Chiang Mai. The inclusion criteria were age $\geq 21$ years, symptomatic coronary artery disease, signed informed consent, and willingness to participate in all follow-up assessments. The exclusion criteria were patients with known intolerance to antiplatelet/anticoagulant therapy required for $\mathrm{PCI}$, stainless steel, sirolimus or contrast media, planned surgery within six months of PCI unless dual antiplatelet therapy was maintained through the operation, pregnancy and participating in another study before the primary endpoint was assessed. The study protocol was approved by all institutional ethics committees and registered with the Thai Clinical Trials Registry (TCTR), Number TCTR20190325001.

\section{Device description}

The Orsiro SES is an ultra-thin cobalt-chromium stent with hybrid coating. The strut thickness is $60 \mu \mathrm{m}$ for 2.25 to $3.0 \mathrm{~mm}$ and $80 \mu \mathrm{m}$ for $>3.0 \mathrm{~mm}$. The stent's outermost is coated by poly-L-lactic acid(PLLA) polymer with an asymmetrical thickness of $7.5 \mu \mathrm{m}$ on the abluminal stent surface and $3.5 \mu \mathrm{m}$ on the luminal surface (20). The PLLA carries a sirolimus concentration of $1.4 \mu \mathrm{m} / \mathrm{mm}^{2}$; more than $80 \%$ of the drug will elute from the stent over a 90-day. The PLLA slowly degrades via the Krebs cycle causing the polymer breaks down into carbon dioxide and water and completely degrades over 12-15 months (21). After bioresorption is complete, the innermost part of the strut with a passive coating layer of amorphous silicon carbide $\left(\mathrm{PROBIO}^{\circledR}\right)$ remains and acts as a diffusion barrier to reduce ion release, consequently, reduce the risk of inflammation.

\section{Procedure and follow-up}

The severity of the lesion and lesion length were assessed by visual estimation. PCI was performed using standard interventional techniques. The medication, pre- and post-dilation devices were left to the operator's discretion. All patients with chronic coronary syndrome (CCS) and acute coronary syndrome (ACS) were required to received dual antiplatelet therapy (DAPT) for a period of 6 and 12 months, respectively. The follow-up was conducted via telephone interview or clinical visit at 6- and 12 -month post stent implantation. To ensure data quality, $100 \%$ of the data was monitored on-site for endpointrelated data.

\section{Endpoints}

The primary endpoint was target lesion failure (TLF) at 12 months, defined as the composite of cardiac death, target vessel myocardial Infarction (TVMI), clinically driven target lesion revascularization (CD-TLR) and emergent coronary artery bypass graft (CABG).

Secondary endpoints included TLF at six months, target vessel revascularization (TVR), TLR and stent thrombosis according to the academic research consortium (ARC) at 6 and 12 months, clinical device success and clinical procedural success.

Cardiac death is defined as any death due to proximate cardiac cause (e.g. MI, low-output failure, fatal arrhythmia), unwitnessed death or death of unknown cause and all procedure-related deaths, including those related to concomitant treatment. Target vessel myocardial infarction defined as target vessel Q-wave or 
non-Q-wave myocardial infarction. Myocardial infarction was adjudicated according to the universal definition of myocardial infarction (22). Periprocedural myocardial infarction is defined as an increased in cardiac troponin greater than $3 \times 99$ th percentile URL in subjects with normal baseline troponin values. However, the protocol did not mandate to routinely collect the biomarkers pre- and post-procedure. Clinically driven target lesion revascularization is defined as any repeat revascularization of the target lesion with demonstration of a positive functional clinical investigation, ischemic electrocardiography changes at rest in a distribution consistent with the target vessel, or ischemic symptoms and in-lesion diameter stenosis $\geq 50 \%$ by quantitative coronary angiogram. Target vessel revascularization is defined as any repeat percutaneous intervention or surgical bypass of any segment of the target vessel including the target lesion.

Clinical device success was defined as post-procedural residual stenosis of less than $20 \%$ by visual estimation and without the use of a device outside the assigned treatment strategy. Clinical procedural success was defined as device success without ischemiadriven major adverse cardiac event (MACE) during the hospital stay up to the first seven days post-index procedure. Major adverse cardiac event (MACE) is defined as the composite of cardiac death, TVMI, CD-TLR, and emergent CABG.

In the case of multiple lesions treatment, all treated lesions must meet the procedural success definition. Study data were collected and managed using REDCap electronic data capture tools hosted at Chiang Mai University.

\section{Statistical methods}

Four subgroups were pre-defined for statistical analysis; i) diabetes patients, small vessels $(\leq 2.75 \mathrm{~mm})$, chronic total occlusion (CTO), and acute myocardial infarction (AMI).

Categorical variables were reported with frequencies and percentages. The continuous variables were summarized as mean \pm standard deviation (SD) or median and interquartile ranges (IQR 1st-3rd) as appropriate. The primary and secondary endpoints were analyzed based on the intention-to-treat population. KaplanMeier method was used to demonstrate the time to event of the primary endpoint. The comparison among the predefined subgroups was performed with the logrank test. A two-sided $p$-value $<0.05$ was considered statistically significant. Statistical analysis was performed by IBM SPSS Statistics version 26.0 (IBM Corp, Armonk, NY, USA).

\section{Results}

Patients characteristics

A total of 150 patients were included between March 2019 and January 2020 (Fig. 1). The baseline patient characteristics of the entire cohort and prespecified subgroups were summarized in Table 1 . The mean age of the patients was $67 \pm 12$ years, $68 \%$ were male, and $32 \%$ had diabetes. The proportion of patients with ACS (53.3\%) was numerically higher than patients with CCS (46.7\%). On average, $18 \%$ of the patients had chronic kidney disease (defined as estimated glomerular filtration rate $<60 \mathrm{ml} / \mathrm{min} / 1.73 \mathrm{~m}^{2}$ ) and previous myocardial infarction. Among patients presenting with ACS, cardiogenic shock was noted in 2 patients (1.3\%). Of 80 culprit lesions, 19 lesions (23.8\%) demonstrated thrombus. DAPT was continued until 12 months in $92.0 \%$ of the patients.

\section{Angiographic and procedural characteristics}

Among 150 patients, 212 lesions were treated with study stents at the index procedure. Seventeen patients with 23 lesions were further scheduled for stage PCI, with the median interval from index PCI to the stage PCI date was 38.0 (IQR 27.5-66.3) days. Finally, 235 lesions were treated with Orsiro SES stents. Baseline angiographic characteristics were tabulated in Table 2. The left anterior descending artery (51.1\%) was frequently treated with the study stent followed by the right coronary artery (26.0\%), left circumflex (18.7\%) and left main (4.3\%), respectively. Nearly three-quarters of the lesions were type B2/C (72.5\%), and $20.9 \%$ were bifurcation lesions. Of all treated lesion, small vessels and CTO were observed in 39.4\% and $10.2 \%$, respectively.

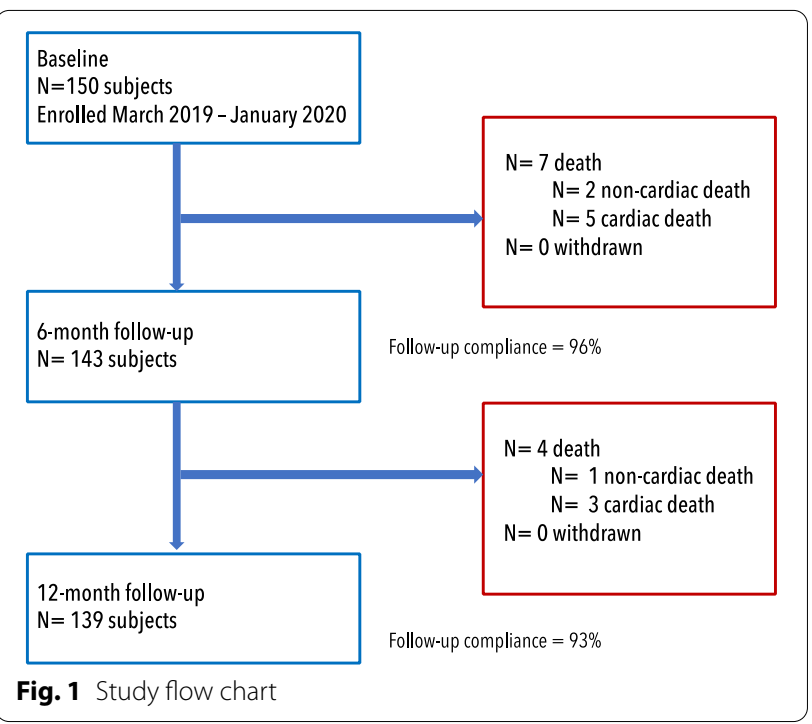


Table 1 Baseline clinical characteristics

\begin{tabular}{|c|c|c|c|c|c|}
\hline & $\begin{array}{l}\text { All population } \\
\mathrm{N}=150\end{array}$ & $\begin{array}{l}\text { Diabetes } \\
N=48\end{array}$ & $\begin{array}{l}\text { Small vessel } \\
\mathrm{N}=75\end{array}$ & $\begin{array}{l}\text { Сто } \\
\mathrm{N}=17\end{array}$ & $\begin{array}{l}\text { AMI } \\
N=80\end{array}$ \\
\hline Age, years & $67.2 \pm 12.5$ & $69.7 \pm 10.0$ & $65.8 \pm 13.6$ & $65.4 \pm 15.3$ & $65.2 \pm 13.7$ \\
\hline Men & 102(68.0) & $30(63.8)$ & $46(62.2)$ & $11(64.7)$ & $57(71.3)$ \\
\hline Current smokers & $20(13.3)$ & $3(6.4)$ & 10(13.5) & $4(23.5)$ & 17(18.8) \\
\hline Diabetes & $48(32.0)$ & $\mathrm{n} / \mathrm{a}$ & $27(36.5)$ & $6(35.3)$ & $21(26.3)$ \\
\hline Hypertension & 113(75.3) & $42(89.4)$ & $58(78.4)$ & $13(76.5)$ & $56(70.0)$ \\
\hline Hyperlipidemia & $96(64.0)$ & $34(72.3)$ & $49(66.2)$ & 10(58.8) & $42(52.5)$ \\
\hline Chronic kidney disease & $27(18.0)$ & 15(31.9) & $12(16.2)$ & $5(29.4)$ & 15(18.8) \\
\hline Chronic obstructive pulmonary disease & $5(3.3)$ & $1(2.1)$ & $1(1.4)$ & $1(5.9)$ & $2(2.5)$ \\
\hline Previous coronary revascularization & $27(18.0)$ & $12(25.5)$ & 16(21.6) & $5(29.4)$ & $6(7.5)$ \\
\hline Previous myocardial infarction & $27(18.0)$ & $11(23.4)$ & $12(16.2)$ & $3(17.6)$ & 13(16.3) \\
\hline History of heart failure & 18(12.0) & $6(12.8)$ & 10(13.5) & $3(17.6)$ & $10(12.5)$ \\
\hline History of cancer & $3(2.0)$ & $1(2.1)$ & $3(4.1)$ & $2(11.8)$ & $2(2.5)$ \\
\hline Chronic coronary syndrome & $70(46.7)$ & 26(55.3) & $40(54.1)$ & $8(47.1)$ & $0(0.0)$ \\
\hline Acute coronary syndrome & $80(53.3)$ & $21(44.7)$ & $34(45.9)$ & $9(52.9)$ & $80(100.0)$ \\
\hline ST segment elevation MI & $40(50.0)$ & $6(28.6)$ & 19(55.9) & $6(66.7)$ & $40(50.0)$ \\
\hline Non ST segment elevation MI & $40(50.0)$ & 15(71.4) & 15(44.1) & $3(33.3)$ & $40(50.0)$ \\
\hline \multicolumn{6}{|l|}{ Medication at discharge } \\
\hline Aspirin & 147(98) & 45(95.7) & 72(97.3) & 16(94.1) & $78(97.5)$ \\
\hline Clopidogrel & $89(59.7)$ & $33(70.2)$ & $44(59.5)$ & $9(52.9)$ & $36(45.6)$ \\
\hline Ticagrelor & 49(33.8) & 13(28.3) & 23(32.9) & $4(23.5)$ & $38(48.7)$ \\
\hline Prasugrel & $11(7.5)$ & $1(2.2)$ & $7(9.9)$ & $3(17.6)$ & $5(6.4)$ \\
\hline Statin & 140(94.0) & 44(93.6) & 69(93.2) & 16(94.1) & 72(91.1) \\
\hline DAPT at 12 months & $121(87.1)$ & $36(83.7)$ & $60(88.2)$ & $15(100.0)$ & 69(92.0) \\
\hline
\end{tabular}

Data shown in $\mathrm{n}(\%)$ or mean $\pm \mathrm{SD}$

$A M I$ acute myocardial infarction; CTO chronic total occlusion; DAPT dual antiplatelet therapy

Table 3 summarizes the procedural characteristics. Predilation was performed in $91.9 \%$ of the treated lesion and predominately performed with semi-compliance balloon $72.5 \%$. Study stents were implanted in the lesion with a mean reference vessel diameter of $2.93 \pm 0.45 \mathrm{~mm}$ and length of $22.2 \pm 10.8 \mathrm{~mm}$. Postdilation was conducted in $69.9 \%$ and usually done with non-compliance balloon with the mean inflation pressure of $16.5 \pm 4.0$ atmosphere and maintain pressure at 23.0(IQR 13.3-38.8) seconds. Among 49 bifurcation lesions, 47 lesions (95.9\%) and 2 lesions (4.1\%) were treated with provisional and two-stent technique, respectively. Intracoronary imaging-guided PCI was employed in $6.8 \%$ of the lesions. Clinical device success was $100 \%(235 / 235)$ of the lesions with clinical procedural success was $98 \%(147 / 150)$ of the patients. Three patients failed to achieve clinical procedural success due to the cardiac death on days 1,4,5 after index procedure. All of them presented with acute ST-elevation myocardial infarction (STEMI).

\section{Clinical outcomes}

Clinical data at 6 months and 12 months was available in $96 \%$ and $93 \%$ of the patients, respectively (median follow-up duration was 372 days [IQR 367-380]). The primary endpoint, TLF at 12 months, occurred in eight patients $(5.3 \%)$, predominately caused by cardiac death. Among eight patients who died, half of them presented with ST-elevation myocardial infarction and died after the PCI procedure on days 1 to 13 (three cases died from the complications related to AMI and one case from acute decompensated heart failure). In pre-specified subgroups, the TLF at 12 months was $6.4 \%$ in diabetic patients, $4.1 \%$ in small vessels, $5.9 \%$ in CTOs and $5.0 \%$ in AMI patients (Fig. 2). All clinical outcomes were detailed in Table 4. Interestingly, the occurrence of TVMI and CD-TLR were null. One patient received TVR at day 265, two patients had definite or probable stent thrombosis. One probable subacute stent thrombosis was suspected due to unexplained death at home after being discharged from hospital one-day post-procedure. One definite late 
Table 2 Angiographic characteristics

\begin{tabular}{|c|c|}
\hline & $\begin{array}{l}\text { All population } \\
\mathrm{n}=150, \mathrm{~L}=235\end{array}$ \\
\hline \multicolumn{2}{|l|}{ Vascular access } \\
\hline Femoral & $129 / 169$ \\
\hline Radial & $38 / 169$ \\
\hline Brachial & $2 / 169$ \\
\hline \multicolumn{2}{|l|}{ Target vessel } \\
\hline Left anterior descending & $120(51.1)$ \\
\hline Left circumflex artery & $44(18.7)$ \\
\hline Right coronary artery & $61(26.0)$ \\
\hline Left main & $10(4.3)$ \\
\hline \multicolumn{2}{|l|}{ AHA/ACC lesion classification } \\
\hline $\mathrm{A} / \mathrm{B} 1$ & $65(27.5)$ \\
\hline $\mathrm{B} 2 / \mathrm{C}$ & $171(72.5)$ \\
\hline Preprocedural TIMI 3 & $164(69.5)$ \\
\hline \multicolumn{2}{|l|}{ No. of target lesions (per patient) } \\
\hline 1 & $92(61.3)$ \\
\hline 2 & $36(24.0)$ \\
\hline 3 & 15(10.0) \\
\hline 4 & $5(3.3)$ \\
\hline 5 & $2(1.3)$ \\
\hline Moderate to heavy calcification* & $38(16.1)$ \\
\hline Bifurcation lesion & $49(20.9)$ \\
\hline Moderate to excessive tortuous vessel & $30(12.7)$ \\
\hline Eccentric lesion & 187(79.2) \\
\hline Lesion with thrombus & $13(5.5)$ \\
\hline Chronic total occlusion & $24(10.2)$ \\
\hline Obstruction length, mm & $22.2 \pm 10.8$ \\
\hline Reference lumen diameter, mm & $2.93 \pm 0.45$ \\
\hline Small vessel $\leq 2.75 \mathrm{~mm}$ & 93(39.4) \\
\hline
\end{tabular}

Data shown in $\mathrm{n}(\%)$ or mean $\pm \mathrm{SD}$ *Moderate calcification is defined as radiopacities noted only during the cardiac cycle before contrast injection. Severe calcification is defined as radiopacities seen without cardiac motion before contrast injection. TIMIThrombolysis in Myocardial Infarction

stent thrombosis was incidentally observed during coronary angiography for primary PCI to the non-target vessel at day 333.

\section{Discussion}

The present study investigated the Thai experience with ultrathin BP-SES in real-world practice. The main findings of the study were as follows: 1) Orsiro SES implantation in Thai patients has TLF rate of $5.3 \%$ that was consistent with previous reports; 2) the outcomes in the prespecified subgroup were not different from the control population.

The Orsiro SES platform has been studied in $>50,000$ patients. The clinical outcomes of the Thailand Orsiro registry were concordant with several studies both in
Table 3 Procedural characteristics

\begin{tabular}{|c|c|}
\hline & $\begin{array}{l}\text { All population } \\
\mathrm{n}=150, \mathrm{~L}=235\end{array}$ \\
\hline Diameter stenosis, \% & $84.9 \pm 11.8$ \\
\hline \multicolumn{2}{|l|}{ Pre-dilation } \\
\hline Pre-dilatation & 217(91.9) \\
\hline Cutting or scoring balloon & $10(4.2)$ \\
\hline Non-compliance balloon & $35(14.8)$ \\
\hline Semicompliance balloon & $171(72.5)$ \\
\hline Nominal pre-dilation balloon diameter, mm & $2.49 \pm 1.00$ \\
\hline Pre-dilation balloon length, mm & $17.1 \pm 4.9$ \\
\hline \multicolumn{2}{|l|}{ Stent procedure } \\
\hline \multicolumn{2}{|l|}{ No. of study stents implanted } \\
\hline Per patient & $1.7 \pm 1.1$ \\
\hline Per lesion & $1.1 \pm 0.3$ \\
\hline Per vessel & $1.4 \pm 0.7$ \\
\hline Total length of implanted stents, mm & $26.9 \pm 12.2$ \\
\hline Mean nominal device diameter, mm & $2.97 \pm 0.46$ \\
\hline Overlapping stents & $18(7.6)$ \\
\hline Bifurcation lesions treated with provisional stenting & $47(95.9)$ \\
\hline Bifurcation lesions treated with two-stent technique & $2(4.1)$ \\
\hline \multicolumn{2}{|l|}{ Number of stents per lesion } \\
\hline 1 & $217(92.3)$ \\
\hline 2 & $16(6.8)$ \\
\hline 3 & $1(0.4)$ \\
\hline 4 & $1(0.4)$ \\
\hline Intracoronary imaging in the procedure & $16(6.8)$ \\
\hline \multicolumn{2}{|l|}{ Post-dilation } \\
\hline Post-dilation & $165(69.9)$ \\
\hline Nominal post-dilation balloon diameter, mm & $3.12 \pm 0.53$ \\
\hline Post-dilation balloon length, mm & $15.5 \pm 6.2$ \\
\hline NC used for post-dilation & $110(67.1)$ \\
\hline Max applied pressure, atm & $16.5 \pm 4.0$ \\
\hline Cumulative inflation time & $23.0(13.3-38.8)$ \\
\hline Device success & $235(100)$ \\
\hline Procedure success & 147(98.0) \\
\hline
\end{tabular}

Data shown in $\mathrm{n}(\%)$ or mean $\pm \mathrm{SD}$ or median (interquartile range $1 \mathrm{st}-3 \mathrm{rd}$ )

registries and RCTs. The TLF rates of the present study were $5.3 \%$ compared to $5.1 \%$ in all-comer registry BIOFLOW-III (17) (Real-world experience with a novel biodegradable polymer sirolimus-eluting stent), and $6 \%$ in BIOFLOW-V (10) (Ultrathin, bioresorbable polymer sirolimus-eluting stents versus thin, durable polymer everolimus-eluting stents in patients undergoing coronary revascularization) randomized trial. Thus, the TLF rates of the present study align with previous data.

However, other RCTs reported the TLF rates less than 5\%; the incidence ranged from $3.2 \%$ to $4.2 \%$ (11, 12, 23-25). The population included in the RCTs were 


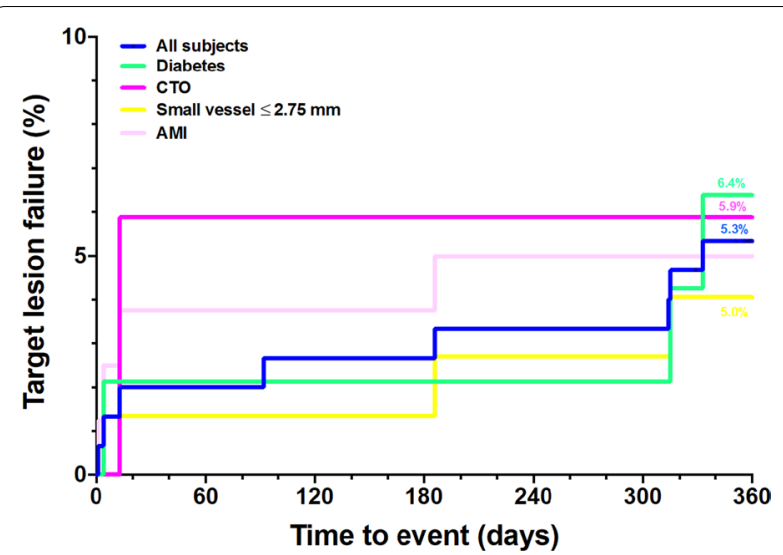

Fig. 2 Kaplan-Meier event estimates for target lesion failure

selected population and, by design has excluded poor prognosis patients; these might explain the low TLF rates in RCTs compared to the present study.

Notably, the primary outcomes of the present study were driven by cardiac death in which the majority of them occurred as the complications of the initial presentation with AMI. Post-discharge cardiac death within 14 days were 3 patients (2.0\%). By contrast, the major events in other trials were TVMI or TLR with the low incidences of cardiac death of $0 \%$ to $1.3 \%(10,11,17,23)$. The high incidence of cardiac death in the present study might be explained by the half of the population was ACS patients. Though the previous publications have reported the proportion of ACS patients from $32.5 \%$ to $53 \%$, it should be noted that the patients with MI in such trials were eligible for enrollment after MI onset $>72 \mathrm{~h}$ (10, 11). The inclusion criteria were in contrast to the present study that enrolled all patients who received Orsiro SES without the limitation of MI onset. To date, two trials were testing the safety and efficacy of Orsiro in STEMI patients; HEROES (16) (Hard Events AfteR Orsiro Sirolimus-Eluting Stent in STEMI: A Multicenter Registry) and BIOSTEMI (12) (Biodegradable polymer sirolimuseluting stents versus durable polymer everolimus-eluting stents in patients with ST-segment elevation myocardial infarction) randomized trial, the cardiac death rates at 12 months were $4.8 \%$ and $3 \%$, respectively. This all-comer study has reproducible results as in the dedicated ACS trial.

The absence of TVMI and CD-TLR events in the current study is deserved for discussion. The BIOFLOW-V (10) trial has reported TVMI rates of $5 \%$, in contrast to the present study that was null. The difference might be explained by the study protocol that did not intended to capture periprocedural MI events. Besides, periprocedural MI in the ACS setting, especially STEMI, was difficult to determine in real-world practice. The zero events of CD-TLR were lower than that reported 3.0\% in all-comer registry BIOFLOW-III (17), $2.0 \%$ in randomized controlled trials $(10,11,23,26)$ except $1.0 \%$ in BIOSTEMI (12) trial. Low incidence of TLR might be explained by meticulous post-dilation performed in the present registry. According to the BIOFLOW-III (17) registry, post-dilation was performed only $25.3 \%$ whereas the post-dilation rates of the Thailand Orsiro registry were $69.9 \%$ with a high proportional of non-compliance balloon (67.1\%) at high pressure (16.5 atmosphere). In

Table 4 Adverse cardiac events at 6 and 12 months

\begin{tabular}{|c|c|c|c|c|c|c|}
\hline \multirow[t]{2}{*}{ Event } & \multirow{2}{*}{$\begin{array}{l}\text { Total events at } \\
6 \text { months } \\
n=150\end{array}$} & \multirow{2}{*}{$\begin{array}{l}\text { Total events at } \\
12 \text { months } \\
n=150\end{array}$} & \multirow{2}{*}{$\begin{array}{l}\text { Diabetes } \\
\mathrm{N}=\mathbf{4 8}\end{array}$} & \multirow{2}{*}{$\begin{array}{l}\text { Small vessel } \\
\mathrm{N}=75\end{array}$} & \multirow{2}{*}{$\begin{array}{l}\text { CTO } \\
\mathrm{N}=17\end{array}$} & \multirow{2}{*}{$\begin{array}{l}\text { AMI } \\
\mathrm{N}=80\end{array}$} \\
\hline & & & & & & \\
\hline Target lesion failure & $5(3.3)$ & $8(5.3)$ & $3(6.4)$ & $3(4.1)$ & $1(5.9)$ & $4(5.0)$ \\
\hline Cardiac death & $5(3.3)$ & $8(5.3)$ & $3(6.4)$ & $3(4.1)$ & $1(5.9)$ & $4(5.0)$ \\
\hline Target vessel myocardial infarction & $0(0.0)$ & $0(0.0)$ & $0(0.0)$ & $0(0.0)$ & $0(0.0)$ & $0(0.0)$ \\
\hline Emergent CABG surgery & $0(0.0)$ & $0(0.0)$ & $0(0.0)$ & $0(0.0)$ & $0(0.0)$ & $0(0.0)$ \\
\hline Clinically driven target lesion revascularization & $0(0.0)$ & $0(0.0)$ & $0(0.0)$ & $0(0.0)$ & $0(0.0)$ & $0(0.0)$ \\
\hline All-cause death & $7(4.7)$ & $11(7.3)$ & $1(2.1)$ & $6(8.1)$ & $2(11.8)$ & $5(6.3)$ \\
\hline All myocardial infarction & $1(0.7)$ & $2(1.3)$ & $0(0.0)$ & $0(0.0)$ & $0(0.0)$ & $0(0.0)$ \\
\hline Non-target vessel myocardial infarction & $0(0.0)$ & $1(0.7)$ & $0(0.0)$ & $0(0.0)$ & $0(0.0)$ & $0(0.0)$ \\
\hline Target vessel revascularization & $0(0.0)$ & $1(0.7)$ & $0(0.0)$ & $0(0.0)$ & $0(0.0)$ & $1(1.3)$ \\
\hline Non-target vessel revascularization & $0(0.0)$ & $2(1.3)$ & $1(2.1)$ & $0(0.0)$ & $0(0.0)$ & $1(1.3)$ \\
\hline Definite or probable stent thrombosis & $1(0.7)$ & $2(1.3)$ & $1(2.1)$ & $0(0.0)$ & $0(0.0)$ & $1(1.3)$ \\
\hline Definite & $0(0.0)$ & $1(0.7)$ & $1(2.1)$ & $0(0.0)$ & $0(0.0)$ & $0(0.0)$ \\
\hline Probable & $1(0.7)$ & $1(0.7)$ & $0(0.0)$ & $0(0.0)$ & $0(0.0)$ & $1(1.3)$ \\
\hline
\end{tabular}

Data shown in $\mathrm{n}(\%)$. Abbreviation as Table 1; CABG coronary artery bypass graft 
addition, the registry protocol did not determine to perform follow-up angiography; therefore, the incidence of TLR might be underreporting. However, in real-world practice, repeat revascularization will be performed only in patients who present with ischemic symptom. The current analysis provides real-world evidence of TLR rates in unselected patients.

The incidence of stent thrombosis (definite and probable) of the present study was $1.3 \%$ and higher than previous reports $(<1 \%)(10,11,17,23,26)$ except in the BIOSTEMI (12) trial that was $2 \%$. A higher rate of stent thrombosis in the present study may be explained from 1) a small sample size compared to the previous publications $(10,11,17,23,26) ; 2)$ the definition of stent thrombosis followed the first Academic Research Consortium (ARC). The probable stent thrombosis was counted in one case due to unexplained death within the first 30 days (27). If the update ARC-2 criteria (28) were applied in the current study, no case would have probable stent thrombosis since the criteria utilized any myocardial infarction that was related to the territory of the implanted stent without angiographic confirmation of stent thrombosis, regardless of the time after the index procedure (28). However, the incidence of definite stent thrombosis $(0.7 \%)$ was comparable to other trials and still unchanged regardless of the version of ARC definition.

Regarding the regional and ethnic differences, the primary endpoint of the Thailand Orsiro registry is in line with the TLF rate of $4.6 \%$ from the BIOFLOW-III Italian Satellite Registry (14). On the contrary, the incidence of TLF was $2.8 \%$ in the BIOFLOW-III Canada registry (15), $2.2 \%$ in the Japanese subgroup analysis from the BIOFLOW-IV (11) randomized trial. The disparity of Thai patients' TLF rates to other ethnic groups might be explained by the higher proportion of complex lesion (type $\mathrm{B} 2 / \mathrm{C}$ ) and the presentation of acute coronary syndrome.

\section{Limitations}

The present study has several limitations to be addressed. First, the pre- and post-procedural quantitative coronary angiography was not mandated in the protocol. Consequently, the baseline lesion characteristics were based on operator discretion. Second, there was no protocol mandated for pre-dilation, post-dilation according to the study objective. The operator experience would undoubtedly affect the immediate PCI outcomes. However, the study results reflected the real-world practice outcomes when Orsiro SES were implanted in unselected patients and operators. Third, the sample size was small in comparison to previous national registries of the similar platform. In addition, the present study did not have the power to detect differences of the pre-specified subgroup; thus, the results must be interpreted with caution. Fourth, comparison of the number of events to previous publications should be cautiously interpreted due to varied patient clinical settings, different endpoints, and definitions in an individual trials.

\section{Conclusions}

The safety and efficacy of the ultrathin strut sirolimuseluting stent in unselected patients are confirmed in the Thailand Orsiro registry. Despite the high proportion of pre-specified high-risk subgroups, the excellent stent performance was consistent with the overall population.

\section{Abbreviations \\ ACS: Acute coronary syndrome; BP-SES: Bioresorbable polymer sirolimus-elut- ing stent; CABG: Coronary artery bypass graft; CAD: Coronary artery disease; CD-TLR: Clinically driven-target lesion revascularization; CTO: Chronic total occlusion; DES: Drug-eluting stent; PCI: Percutaneous coronary intervention; SES: Sirolimus eluting stent; STEMI: ST-elevation myocardial infarction; TLF: Target lesion failure; TVMI: Target vessel myocardial infarction.}

\section{Acknowledgements}

The authors wish to express their sincere appreciation to their colleagues at the Division of Cardiology, Faculty of Medicine, Chiang Mai University, Chiang Mai, Thailand and Division of Cardiology, Department of Medicine, King Chulalongkorn Memorial Hospital, Bangkok, Thailand.

\section{Authors' contributions \\ WB contributed to the conception, data interpretation, drafting and revised the main manuscript text. PS performed the statistical analysis, interpretation of data, drafting and revised the manuscript. SA, VL, TT, JC, SS, WU, SK enrolled the patients, collected the data, reviewed the manuscript. All authors read and approved the final manuscript.}

\section{Funding}

The trial was sponsored by the Biotronik Thailand through departmental resources. The sponsor funded an independent data management and analysis center (Chiang Mai University, Chiang Mai, Thailand) for database management and statistical analyses. The sponsor was not involved in conducting the trial, data management, data analysis and data interpretation.

\section{Availability of data and materials}

The datasets used and/or analyzed during the current study are available from the corresponding author on reasonable request.

\section{Declarations}

\section{Ethics approval and consent to participate}

The study was conducted following the principles of the Declaration of Helsinki and was approved by local ethical review boards. The protocol was compliant with ethical standards and privacy rule requirements for research and approved by the research ethic committee, Faculty of Medicine, Chiang Mai University (reference number: REC-25631125-21465) and research affair's, Faculty of Medicine, Chulalongkorn University (Reference Number: 637/61). Written informed consent was obtained from all participants.

\section{Consent for publication}

Not applicable.

\section{Competing interests}

The authors declare that they have no competing interests.

\section{Author details}

${ }^{1}$ Division of Cardiology, Department of Internal Medicine, Faculty of Medicine, Chiang Mai University, Chiang Mai, Thailand. ${ }^{2}$ Division of Cardiology, 
Department of Medicine, King Chulalongkorn Memorial Hospital, 1873 Rama IV Rd., Pathumwan, Bangkok 10330, Thailand.

Received: 17 May 2021 Accepted: 7 October 2021

Published online: 16 October 2021

\section{References}

1. Neumann FJ, Sousa-Uva M, Ahlsson A, Alfonso F, Banning AP, Benedetto U, et al. 2018 ESC/EACTS Guidelines on myocardial revascularization. Eur Heart J. 2019;40(2):87-165.

2. Byrne RA, Serruys PW, Baumbach A, Escaned J, Fajadet J, James S, et al. Report of a European Society of Cardiology-European Association of Percutaneous Cardiovascular Interventions task force on the evaluation of coronary stents in Europe: executive summary. Eur Heart J. 2015;36(38):2608-20.

3. Bangalore S, Toklu B, Patel N, Feit F, Stone GW. Newer-generation ultrathin strut drug-eluting stents versus older second-generation thicker strut drug-eluting stents for coronary artery disease. Circulation. 2018;138(20):2216-26.

4. Lattuca B, Odorico X, Occean BV, Cornillet L, Schmutz L, Ledermann B, et al. Long-term efficacy and safety of newer generation ultrathin strut drug-eluting stents: a systematic review and meta-analysis. Eur Heart J. 2020;41(Supplement_2).

5. Monjur MR, Said CF, Bamford P, Parkinson M, Szirt R, Ford T. Ultrathin-strut biodegradable polymer versus durable polymer drug-eluting stents: a meta-analysis. Open Heart. 2020;7(2).

6. Zhu P, Zhou X, Zhang C, Li H, Zhang Z, Song Z. Safety and efficacy of ultrathin strut biodegradable polymer sirolimus-eluting stent versus durable polymer drug-eluting stents: a meta-analysis of randomized trials. BMC Cardiovasc Disord. 2018;18(1):170.

7. Kalnins U, Erglis A, Dinne I, Kumsars I, Jegere S. Clinical outcomes of silicon carbide coated stents in patients with coronary artery disease. Med Sci Monit. 2002;8(2):Pl16-20.

8. Rzany A, editor Smart Material Silicon Carbide : Reduced Activation of Cells and Proteins on aSiC : H-coated Stainless Steel.

9. Kandzari DE, Koolen JJ, Doros G, Garcia-Garcia HM, Bennett J, Roguin A, et al. Ultrathin bioresorbable-polymer sirolimus-eluting stents versus thin durable-polymer everolimus-eluting stents for coronary revascularization: 3 -year outcomes from the randomized BIOFLOW VTrial. JACC CardiovasC Interv. 2020;13(11):1343-53.

10. Kandzari DE, Mauri L, Koolen JJ, Massaro JM, Doros G, Garcia-Garcia HM, et al. Ultrathin, bioresorbable polymer sirolimus-eluting stents versus thin, durable polymer everolimus-eluting stents in patients undergoing coronary revascularisation (BIOFLOW V): a randomised trial. Lancet. 2017;390(10105):1843-52.

11. Saito S, Toelg R, Witzenbichler B, Haude M, Masotti M, Salmeron R, et al. BIOFLOW-IV, a randomised, intercontinental, multicentre study to assess the safety and effectiveness of the Orsiro sirolimus-eluting stent in the treatment of subjects with de novo coronary artery lesions: primary outcome target vessel failure at 12 months. Eurolntervention. 2019;15(11):e1006-13.

12. Iglesias JF, Muller O, Heg D, Roffi M, Kurz DJ, Moarof I, et al. Biodegradable polymer sirolimus-eluting stents versus durable polymer everolimuseluting stents in patients with ST-segment elevation myocardial infarction (BIOSTEMI): a single-blind, prospective, randomised superiority trial. Lancet. 2019;394(10205):1243-53.

13. Roguin A, Kandzari DE, Marcusohn E, Koolen JJ, Doros G, Massaro JM, et al. Subgroup analysis comparing ultrathin, bioresorbable polymer sirolimus-eluting stents versus thin, durable polymer everolimus-eluting stents in acute coronary syndrome patients. Circ Cardiovasc Interv. 2018;11(10):e007331.

14. Bartorelli AL, Versaci F, Briguori C, Tomai F, Aprigliano G, Poli A, et al. The BIOFLOW-III Italian Satellite Registry: 18-month results of the Orsiro stent in an all-comer high-risk population. J Cardiovasc Med (Hagerstown). 2019;20(7):464-70.

15. Boukhris M, Potter BJ, Fam NP, Matteau A, Graham JJ, Gobeil F, et al. Safety and performance of the Orsiro Sirolimus-eluting stent in the treatment of all-comers patient population in daily clinical practice. Cardiovasc Revasc Med. 2020;21(11):1348-54.

16. De Marzo V, Parisi R, Caruso M, D'Amario D, Annibali G, Manganiello V, et al. Hard Events AfteR Orsiro Sirolimus-Eluting Stent (HEROES) in STEMI: a multicenter registry. J Invasive Cardiol. 2020;32(12):E331-7.

17. Waltenberger J, Brachmann J, van der Heyden J, Richardt G, Frobert $\mathrm{O}$, Seige $\mathrm{M}$, et al. Real-world experience with a novel biodegradable polymer sirolimus-eluting stent: twelve-month results of the BIOFLOW-III registry. Eurolntervention. 2016;11(10):1106-10.

18. Waltenberger J, Brachmann J, van der Heyden J, Richardt G, Frobert $\mathrm{O}$, Seige $M$, et al. Five-year results of the Bioflow-III registry: real-world experience with a biodegradable polymer sirolimus-eluting stent. Cardiovasc Revasc Med. 2020;21(1):63-9.

19. Buccheri S, Sarno G, Erlinge D, Renlund H, Lagerqvist B, Grimfjard P, et al. Clinical Outcomes with Unselected Use of an Ultrathin-Strut SirolimusEluting Stent: A Report from the Swedish Coronary Angiography and Angioplasty Registry (SCAAR). Eurolntervention. 2020.

20. Forrestal BJ, Case BC, Yerasi C, Garcia-Garcia HM, Waksman R. The Orsiro Ultrathin, bioresorbable-polymer sirolimus-eluting stent: a review of current evidence. Cardiovasc Revasc Med. 2020;21 (4):540-8.

21. Simamora P, Chern W. Poly-L-lactic acid: an overview. J Drugs Dermatol. 2006;5(5):436-40.

22. Thygesen K, Alpert JS, Jaffe AS, Simoons ML, Chaitman BR, White HD, et al. Third universal definition of myocardial infarction. Eur Heart J. 2012;33(20):2551-67.

23. von Birgelen C, Zocca P, Buiten RA, Jessurun GAJ, Schotborgh CE, Roguin A, et al. Thin composite wire strut, durable polymer-coated (Resolute Onyx) versus ultrathin cobalt-chromium strut, bioresorbable polymercoated (Orsiro) drug-eluting stents in allcomers with coronary artery disease (BIONYX): an international, single-blind, randomised non-inferiority trial. Lancet. 2018;392(10154):1235-45.

24. Jensen LO, Thayssen P, Maeng M, Ravkilde J, Krusell LR, Raungaard B, et al. Randomized comparison of a biodegradable polymer ultrathin strut sirolimus-eluting stent with a biodegradable polymer biolimus-eluting stent in patients treated with percutaneous coronary intervention: The SORT OUT VII Trial. Circ Cardiovasc Interv. 2016;9(7).

25. Kim SH, Kang SH, Lee JM, Chung WY, Park JJ, Yoon CH, et al. Three-year clinical outcome of biodegradable hybrid polymer Orsiro sirolimuseluting stent and the durable biocompatible polymer Resolute Integrity zotarolimus-eluting stent: A randomized controlled trial. Catheter Cardiovasc Interv. 2020;96(7):1399-406.

26. von Birgelen C, Kok MM, van der Heijden LC, Danse PW, Schotborgh CE, Scholte M, et al. Very thin strut biodegradable polymer everolimus-eluting and sirolimus-eluting stents versus durable polymer zotarolimus-eluting stents in allcomers with coronary artery disease (BIO-RESORT): a three-arm, randomised, non-inferiority trial. Lancet. 2016;388(10060):2607-17.

27. Cutlip DE, Windecker S, Mehran R, Boam A, Cohen DJ, van Es GA, et al. Clinical end points in coronary stent trials: a case for standardized definitions. Circulation. 2007;115(17):2344-51.

28. Garcia-Garcia HM, McFadden EP, Farb A, Mehran R, Stone GW, Spertus J, et al. Standardized end point definitions for coronary intervention trials: the academic research consortium-2 consensus document. Circulation. 2018;137(24):2635-50.

\section{Publisher's Note}

Springer Nature remains neutral with regard to jurisdictional claims in published maps and institutional affiliations. 